\title{
Strategies for the expansion of human induced pluripotent stem cells as aggregates in single-use Vertical-Wheel ${ }^{\mathrm{TM}}$ bioreactors
}

Diogo E. S. Nogueira ${ }^{1,2}$, Carlos A. V. Rodrigues ${ }^{1,2^{*}}$ (D, Marta S. Carvalho ${ }^{1,2}$, Cláudia C. Miranda $a^{1,2}$, Yas Hashimura ${ }^{3}$, Sunghoon Jung ${ }^{3}$, Brian Lee ${ }^{3}$ and Joaquim M. S. Cabral ${ }^{1,2}$

\begin{abstract}
Background: Since their inception, human induced pluripotent stem cells (hiPSCs) have held much promise for pharmacological applications and cell-based therapies. However, their potential can only be realised if large numbers of cells can be produced reproducibly on-demand. While bioreactors are ideal systems for this task, due to providing agitation and control of the culture parameters, the common impeller geometries were not designed for the expansion of mammalian cells, potentially leading to sub-optimal results.

Results: This work reports for the first time the usage of the novel Vertical-Wheel single-use bioreactors for the expansion of hiPSCs as floating aggregates. Cultures were performed in the PBS MINI 0.1 bioreactor with $60 \mathrm{~mL}$ of working volume. Two different culture media were tested, mTeSR1 and mTeSR3D, in a repeated batch or fed-batch mode, respectively, as well as dextran sulfate (DS) supplementation. mTeSR3D was shown to sustain hiPSC expansion, although with lower maximum cell density than mTeSR1. Dextran sulfate supplementation led to an increase in 97 and 106\% in maximum cell number when using mTeSR1 or mTeSR3D, respectively. For supplemented media, mTeSR1 + DS allowed for a higher cell density to be obtained with one less day of culture. A maximum cell density of $(2.3 \pm 0.2) \times 10^{6}$ cells $\mathrm{mL} \mathrm{m}^{-1}$ and a volumetric productivity of $(4.6 \pm 0.3) \times 10^{5} \mathrm{celll} s \cdot \mathrm{mL}^{-1} \cdot \mathrm{d}^{-1}$ were obtained after 5 days with mTeSR1 + DS, resulting in aggregates with an average diameter of $346 \pm 11 \mu \mathrm{m}$. The generated hiPSCs were analysed by flow cytometry and QRT-PCR and their differentiation potential was assayed, revealing the maintenance of their pluripotency after expansion.
\end{abstract}

Conclusions: The results here described present the Vertical-Wheel bioreactor as a promising technology for hiPSC bioprocessing. The specific characteristics of this bioreactor, namely in terms of the innovative agitation mechanism, can make it an important system in the development of hiPSC-derived products under current Good Manufacturing Practices.

Keywords: Human induced pluripotent stem cells, Expansion, Aggregates, Fed-batch, Dextran sulfate, Single-use bioreactors, Vertical-Wheel bioreactors

\footnotetext{
* Correspondence: carlos.rodrigues@tecnico.ulisboa.pt

${ }^{1}$ Department of Bioengineering and iBB, Institute for Bioengineering and

Biosciences, Instituto Superior Técnico, Universidade de Lisboa, Av. Rovisco

Pais, 1049-001 Lisbon, Portugal

${ }^{2}$ The Discoveries Centre for Regenerative and Precision Medicine, Lisbon

Campus, Instituto Superior Técnico, Universidade de Lisboa, Lisbon, Portugal

Full list of author information is available at the end of the article
}

(c) The Author(s). 2019 Open Access This article is distributed under the terms of the Creative Commons Attribution 4.0 International License (http://creativecommons.org/licenses/by/4.0/), which permits unrestricted use, distribution, and

reproduction in any medium, provided you give appropriate credit to the original author(s) and the source, provide a link to the Creative Commons license, and indicate if changes were made. The Creative Commons Public Domain Dedication waiver (http://creativecommons.org/publicdomain/zero/1.0/) applies to the data made available in this article, unless otherwise stated. 


\section{Background}

Human pluripotent stem cells (hPSCs), due to their ability to self-renew and to generate cells derived from the three germ layers, have a great potential for drug discovery, disease modelling and, ultimately, Regenerative Medicine applications [1, 2]. Human induced pluripotent stem cells (hiPSCs), first derived in 2007 from reprogramming of adult somatic cells [3, 4], are not only less ethically prohibitive than human embryonic stem cells (hESCs), but also open the way for personalised medicine approaches $[5,6]$.

One of the greatest constraints in using these cells, or their derivatives, for biomedical applications is their expansion to clinically-relevant numbers, which can reach $10^{9}$ cells per patient for Regenerative Medicine settings [7]. Traditional planar cell culture platforms, such as tissue culture plates, are unsuited for these large-scale applications [8]. Alternatively, bioreactors provide a 3D, scalable environment and are compatible with different medium feeding strategies, which can improve cell growth. In fact, planar culture platforms require a "repeated batch" strategy for medium change, where the medium is replaced at fixed time intervals, causing drastic variations in culture parameters such as $\mathrm{pH}$ or the concentration of nutrients, growth factors or metabolites. In contrast, bioreactors open the potential for alternative feeding strategies, such as fed-batch, where concentrated medium is added without replacing the contents of the culture vessel, or perfusion, where there is constant withdrawal of spent medium and replenishment of fresh medium $[9,10]$.

Early studies on the suspension culture of hPSCs as aggregates in bioreactors focused on the optimisation of the process [11-14] including the establishment of xeno-free conditions [15]. More recently, Kropp and colleagues [10] expanded hiPSCs in single-use, instrumented bioreactors, and were able to increase cell yield in $47 \%$ when applying a perfusion feeding strategy over repeated batch culture, obtaining a cell density of $(2.85 \pm 0.34) \times 10^{6}$ cells $\cdot \mathrm{mL}^{-1}$. These studies, however, were performed using common bioreactor systems, such as stirred tank bioreactors, which were developed and extensively used for manufacturing traditional biological products, where the quality of the cells is not the major concern. These bioreactors may not constitute the best solution for hPSC culture as they often require high agitations speeds in order to keep cell aggregates efficiently in suspension, with high shear rates conveyed to the cells by the impeller. As such, new bioreactor configurations are being developed to overcome these problems and allow for large-scale stem cell culture [16].

One example of a novel bioreactor system is the single-use Vertical-Wheel bioreactor (VWBR), available on a wide range of scales, from $100 \mathrm{~mL}$ to $80 \mathrm{~L}$. The agitation in these bioreactors is provided by a large vertical impeller, which, combined with the U-shaped bottom, allows for a better homogenisation of the vessel contents with reduced power input. Consequently, cells are exposed to lower shear stress levels, when compared to traditional alternatives [17].

The VWBR has already been used for some stem cell-related applications, including for the growth of human mesenchymal stem cells [18-20] and, recently, it was proven to allow for the scalable expansion of hiPSCs on microcarriers in xeno-free conditions [21]. While microcarriers provide a surface for the cells to adhere to, thus easing transition from 2D cultures, the cells need to be detached at the end of the culture, increasing the load of the downstream processing and affecting cell quality. Culturing the cells as aggregates may provide a simpler and potentially more costeffective process for large-scale hiPSC production [13, 22]. Moreover, with the VWBR, agitation can be used to control aggregate size, as large aggregates $(>300 \mu \mathrm{m})$ are subjected to diffusion problems to their centre, causing undue cell differentiation or death [23]. To minimise aggregate variability, however, there is a need for additional strategies for size control beyond physical forces. Polysulfated compounds are commonly used in the biopharmaceutical industry, not only for their ability to reduce cell aggregation by modulating charges in the surface of the cell, but also for their anti-apoptotic effect on cells [24, 25]. Dextran sulfate (DS), in particular, has been employed for various cell systems, such as insect [24] or Chinese Hamster Ovary cells [26]. Most notably, DS was recently reported to promote these effects on hPSCs without loss of pluripotency [27], thus, the use of this molecule in bioreactor systems may improve the outcomes in terms of cell expansion.

In this work, hiPSCs were expanded for the first time as aggregates in VWBRs (PBS MINI 0.1), with a working volume of $60 \mathrm{~mL}$ (Fig. 1). The results were validated using a second cell line, evidencing the robustness of this culture system. In order to maximise the potential of this culture set-up, the novel VWBR was also combined with a fedbatch strategy, which was never before described for hiPSC culture, as well as with DS, which allowed to greatly increase the cellular growth in the reactor. The work here performed demonstrates that hiPSCs can be cultured as aggregates in the VWBRs, opening the path for current Good Manufacturing Practice (cGMP)-compliant protocols for expansion, and prospectively, differentiation of hiPSCs for clinical applications.

\section{Results}

\section{VWBRs allow the expansion of hiPSCs as aggregates}

A protocol for expansion of hiPSCs as aggregates in the VWBRs was adapted from similar reports for other types of bioreactors [10]. For initial experiments, mTeSR1 was selected as the culture medium, due to being a feederfree and serum-free medium, which has already been well-documented for the expansion of hiPSCs [28, 29]. 


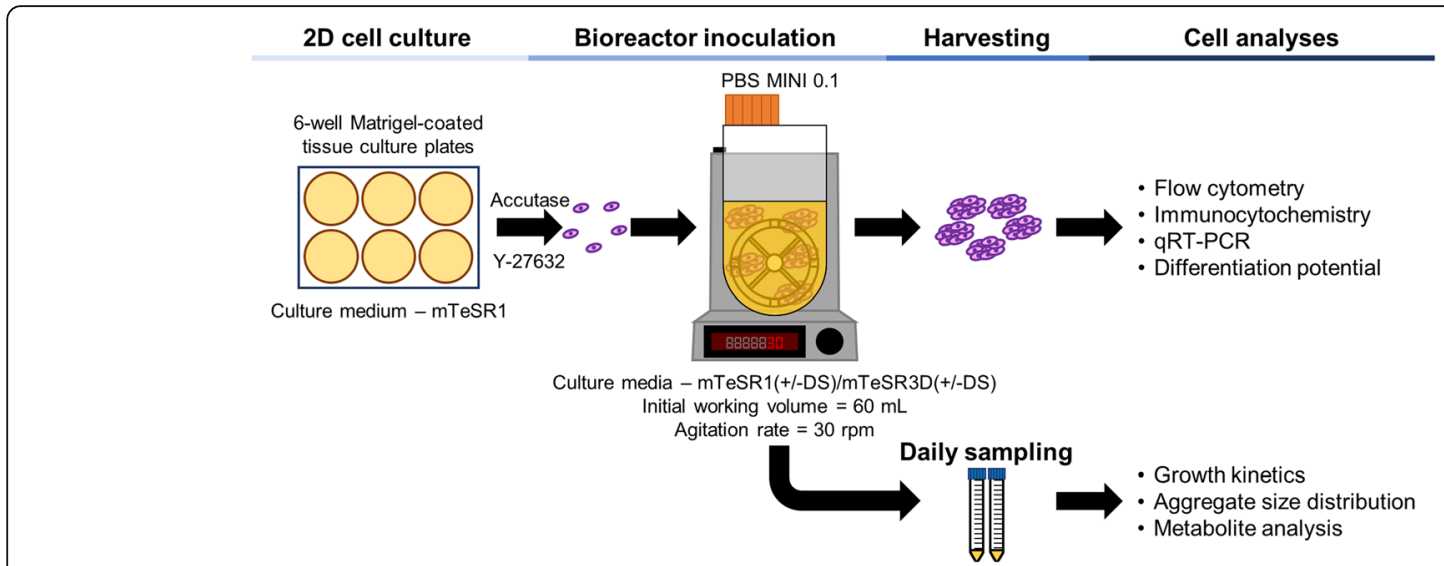

Fig. 1 Workflow of the expansion of hiPSCs as aggregates in WWBRs. Following 2D culture in tissue culture plates, hiPSCs were dissociated into single cells with Accutase and inoculated into the PBS MINI 0.1 bioreactor, where they formed aggregates. The culture was evaluated through daily sampling and analysis of the cells after culture

The PBS MINI 0.1 MAG bioreactor was used with an initial working volume of $60 \mathrm{~mL}$, just enough to cover the vertical wheel, to ensure the optimised hydrodynamic profile of the VWBR [17]. Preliminary tests were performed to determine the minimum stirring speed, which leads to efficient suspension of the aggregates throughout the culture time. Stirring was thus set at $30 \mathrm{rpm}$ since at lower speeds aggregate sedimentation in the bottom of the vessel was observed.

For these initial experiments, two different cell lines were tested (TCLab and Gibco). In these culture conditions, the cells were able to form aggregates which grew throughout time (Fig. 2a, c) and were kept viable through 7 days of culture (Fig. 2b, d). For three independent bioreactor runs, the results were found to be reproducible, in terms of growth kinetics, aggregate size and metabolic profiles. The average growth curve obtained for this culture set-up is depicted in Fig. 2e. A maximum of $(1.2 \pm 0.1) \times 10^{6}$ cells. $\mathrm{mL}^{-1}$ and $(1.0 \pm$ $0.2) \times 10^{6}$ cells $\cdot \mathrm{mL}^{-1}$ were obtained at day 7 post-inoculation with the TCLab and Gibco cell lines, respectively. The average diameter of cell aggregates was gradually increased to respective averages of $409 \pm 25 \mu \mathrm{m}$ and $338 \pm$ $27 \mu \mathrm{m}$ at day 7 (Fig. 2f). The dispersion of each experiment was measured through the coefficient of variation (Fig. 2g). For the TCLab cell line, the coefficient of variation was at its highest at day $1(39 \pm 5 \%)$, but generally decreased to $\sim 30 \%$ in the last days of culture. For the Gibco cell line, it consistently remained below 25\%. Aggregate diameter distributions at days 1,4 and 7 are shown for a representative experiment in Fig. 2h, i. Culture medium supernatant analysis revealed that glucose levels were never depleted below $35 \%$ of fresh medium values (Fig. 2j), and lactate did not accumulate to concentrations over $16 \mathrm{mM}$ (Fig. 2k). The yield of lactate from glucose remained between $\sim 1.7$ and $\sim 2.1$ throughout culture (Fig. 2l). These results overall show the implemented culture system to be robust, with similar results obtained for two different hiPSC lines.

\section{Fed-batch feeding sustains hiPSC growth but with lower cell expansion than repeated batch}

Following the proof-of-concept experiments, demonstrating the use of the PBS MINI 0.1 for the expansion of two different hiPSC lines, different culture conditions were evaluated. In the previous experiments, mTeSR1 was used in repeated batch mode where, from day 2 onwards, $80 \%$ of the medium was changed daily. This approach results in significant variations in the culture parameters (e.g., glucose and lactate, as shown in Fig. 2g, h), which can have a negative effect on cell growth. However, while critical glucose and lactate concentrations were never reached with this feeding regime, daily medium changes are necessary in order to replenish components required to maintain the pluripotency of the cells, such as basic fibroblast growth factor (bFGF) and transforming growth factor $\beta$ (TGF $\beta$ ). mTeSR3D is an alternative formulation to mTeSR1, optimised for cell growth in suspension as the necessary growth factors are replenished through daily addition of a concentrated supplement. Thus, this fed-batch regime can allow for sustained maintenance of pluripotency factors, while causing less severe changes in other culture parameters.

Aggregate formation with mTeSR3D was observed (Fig. 3a), and these aggregates remained viable until the end of culture (Fig. 3b). Despite the intrinsic advantages of this feeding regime, culture in mTeSR3D presented a similar, albeit lower, cell growth profile when compared to mTeSR1 (Fig. 3c), with a maximum of $(8.8 \pm 1.6) \times$ $10^{5}$ cells $\cdot \mathrm{mL}^{-1}$ at day 7 . With mTeSR3D, aggregate diameter averaged $367 \pm 18 \mu \mathrm{m}$ at day 7 (Fig. 3d) with a coefficient of variation between $\sim 25-40 \%$ (Fig. 3e) and 


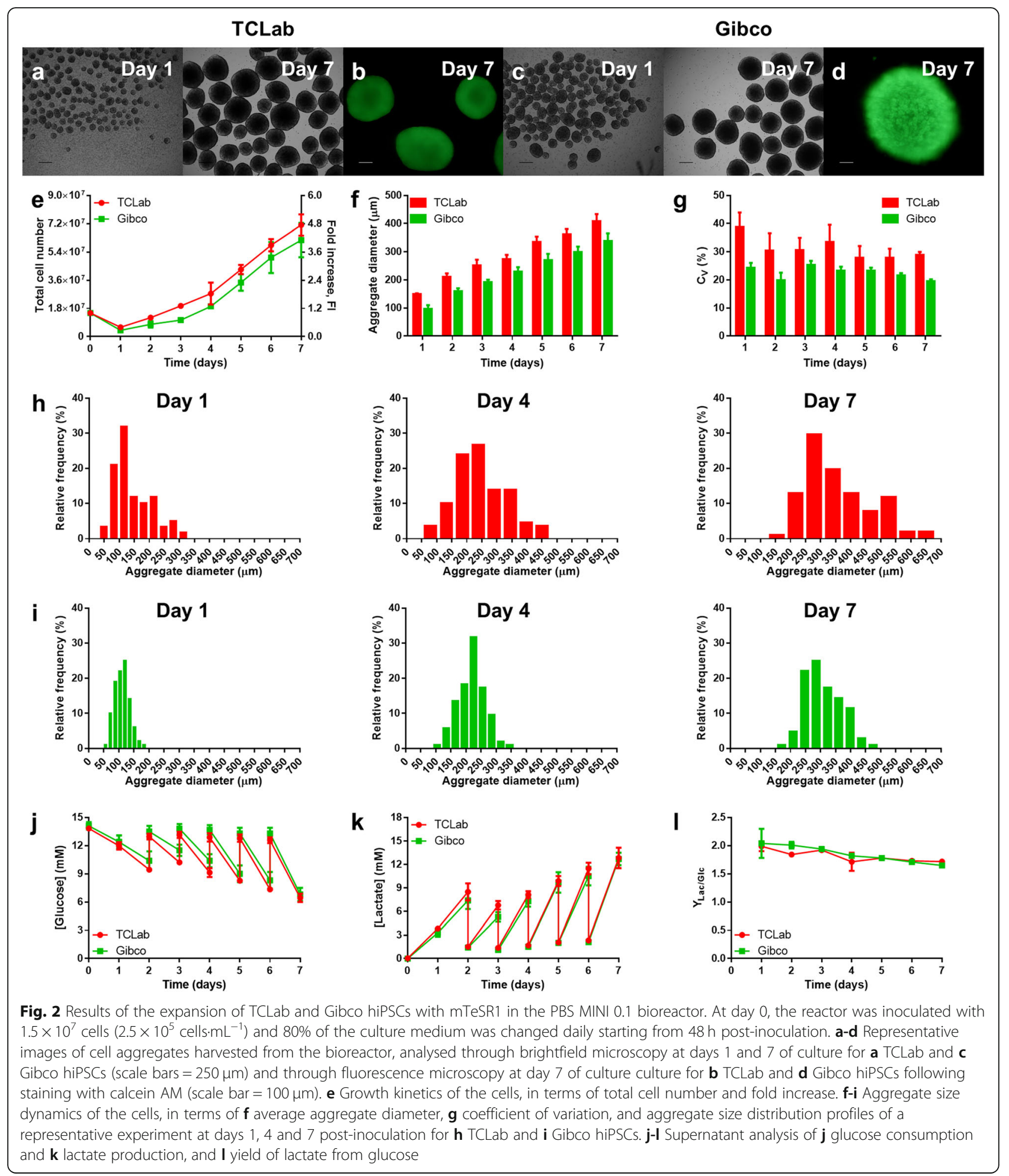

following the distribution shown in Fig. 3f. These values were similar to those obtained with mTeSR1.

Expectedly, the fed-batch regime led to a more thorough consumption of glucose (Fig. 3g) without complete depletion ( 50\% prior to the medium change at day 4 and $\sim$
$30 \%$ at day 7). Higher accumulation of lactate (Fig. 3h) was also observed, to a maximum of $19.3 \mathrm{mM}$ at day 7 , within the generally-considered inhibitory threshold for hPSCs of $15-20 \mathrm{mM}[30,31]$. The yield of lactate from glucose (Fig. 3i) was maintained between $\sim 1.8$ and $\sim 2.0$ 

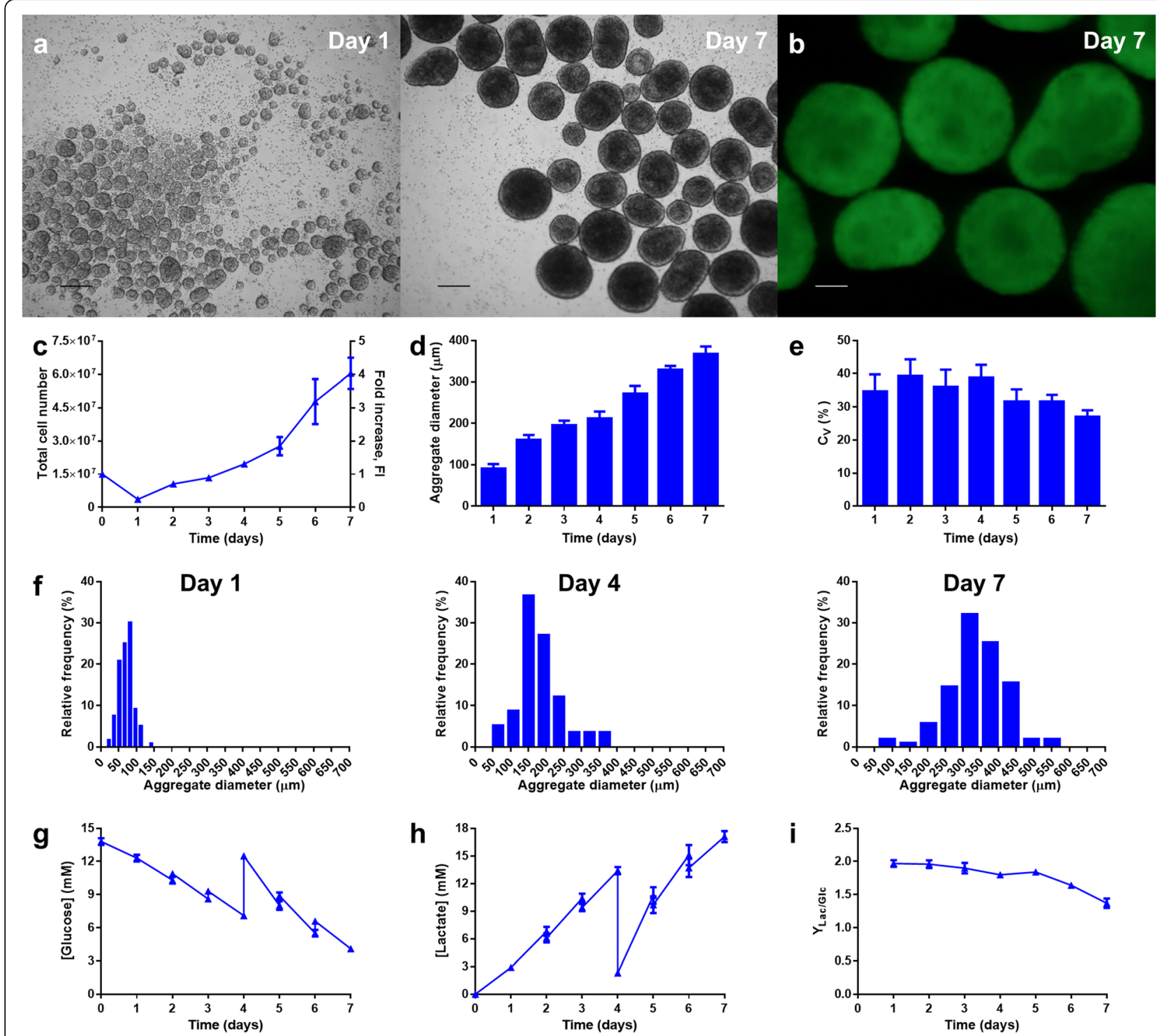

Fig. 3 Results of the expansion of TCLab hiPSCs with mTeSR3D in the PBS MINI 0.1 bioreactor. At day 0 , the reactor was inoculated with $1.5 \times 10^{7}$ cells $\left(2.5 \times 10^{5}\right.$ cells $\left.\mathrm{mL}^{-1}\right)$ and $6.7 \mathrm{~mL}$ of feed medium was added daily starting from $48 \mathrm{~h}$ post-inoculation, with a full medium change at day 4 . a-b Representative images of cell aggregates harvested from the bioreactor, analysed through a brightfield microscopy at days 1 and 7 of culture (scale bars $=250 \mu \mathrm{m}$ ) and $\mathbf{b}$ fluorescence microscopy at day 7 of culture following staining with calcein AM (scale bar $=100 \mu \mathrm{m}$ ). $\mathbf{c}$ Growth kinetics of the cells, in terms of total cell number and fold increase. $\mathbf{d}$-f Aggregate size dynamics of the cells, in terms of $\mathbf{d}$ average aggregate diameter, e coefficient of variation, and $\mathbf{f}$ aggregate size distribution profiles of a representative experiment at days 1, 4 and 7 post-inoculation. $\mathbf{g}$ $\mathbf{i}$ Supernatant analysis of $\mathbf{g}$ glucose consumption and $\mathbf{h}$ lactate production, and $\mathbf{i}$ yield of lactate from glucose

in the first 5 days of culture, indicating an essentially glycolytic metabolism. In fact, the growth of hiPSCs is sustained by rapid consumption of glucose via conversion to lactate (glycolysis) even in the presence of oxygen, in a phenomenon known as the Warburg effect $[32,33]$. At days 6 and 7 , the yield of lactate from glucose decreased to $1.64 \pm 0.03$ and $1.37 \pm 0.07$, suggesting an increasing shift to oxidative phosphorylation (OXPHOS). Nevertheless, this feeding regimen seems to be sufficient for the hiPSC maintenance, while minimising the variations in the culture environment to which the cells are subjected.

\section{Dextran sulfate supplementation improves cell yield}

As an attempt to improve cell growth while reducing aggregate size and size variability, both culture media used in this study, mTeSR1 and mTeSR3D, were tested with DS supplementation in the VWBRs. DS-supplemented media allowed the hiPSCs to form aggregates and their viability at day 7 was not compromised (Fig. 4a-d). Growth curves (Fig. 4e 


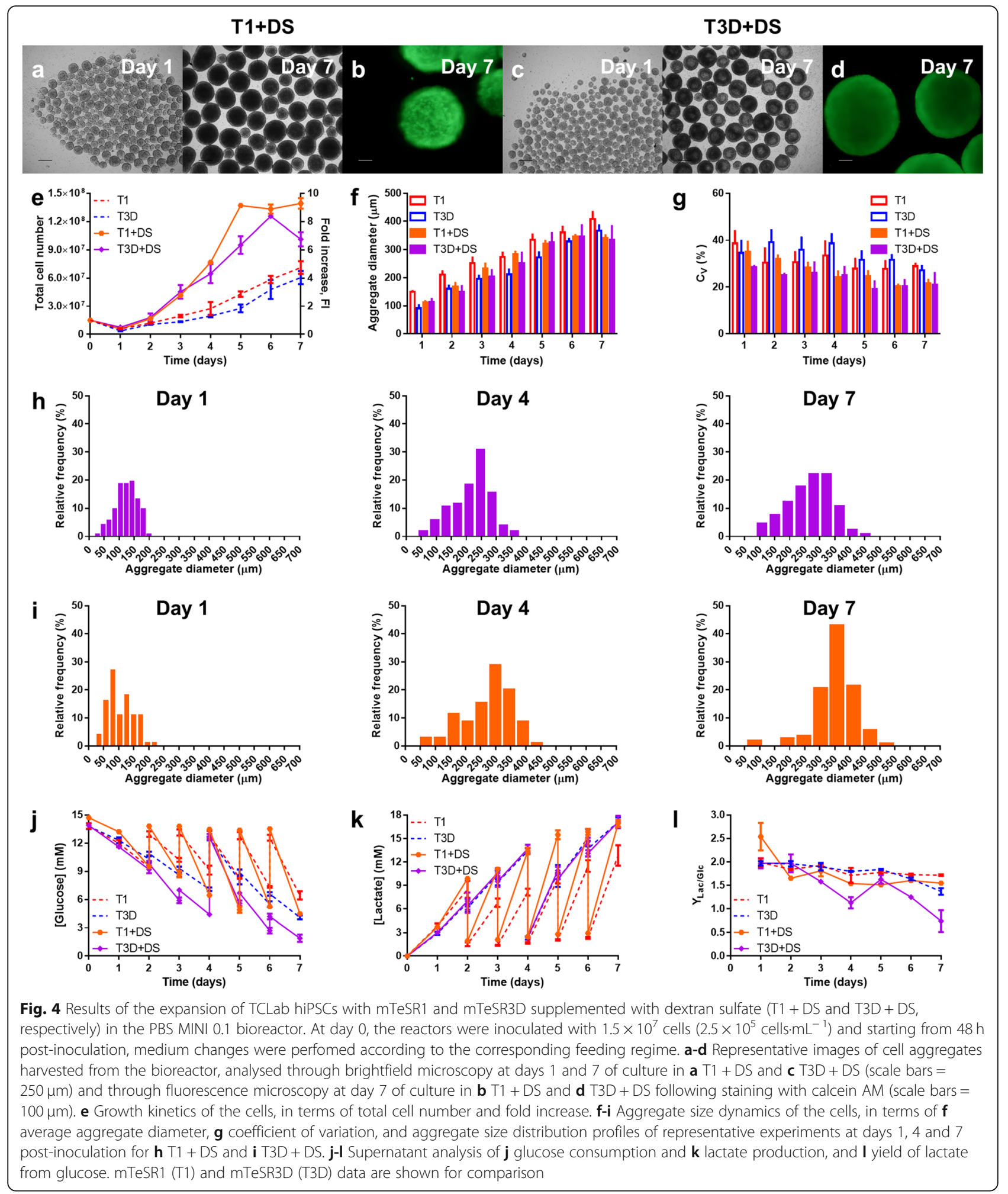

and Additional file 1: Figure S1) show the hiPSCs to grow exponentially from $24 \mathrm{~h}$ of culture, reaching the maximum at day 5 for mTeSR 1 + DS or day 6 with mTeSR3D + DS, following which the cell density stagnated or decreased, respectively. Supplementation with DS led to a higher maximum fold expansion with both media, $9.3 \pm 0.6((2.3 \pm$ $0.2) \times 10^{6}$ cells $\cdot \mathrm{mL}^{-1}$ ) for $\mathrm{mTeSR} 1+\mathrm{DS}$ and $8.4 \pm 0.1$ $\left((1.79 \pm 0.03) \times 10^{6} \quad\right.$ cells $\left.\cdot \mathrm{mL}^{-1}\right)$ for mTeSR3D + DS, 
representing a 97 and 106\% increase in the number of cells versus the respective media without DS. Additionally, since the maximum in the number of cells is obtained 1 to 2 days earlier, these conditions also led to higher volumetric productivities of $(4.6 \pm 0.3) \times 10^{5}$ cells $\cdot \mathrm{mL}^{-1} \cdot \mathrm{d}^{-1}$ and $(2.99 \pm$ $0.05) \times 10^{5} \quad$ cells $\cdot \mathrm{mL}^{-1} \cdot \mathrm{d}^{-1}$ for mTeSR $1+\mathrm{DS}$ and mTeSR3D + DS, respectively, having increased 170 and 149\% from non-supplemented media.

The maximum aggregate sizes obtained at the plateau were $346 \pm 11 \mu \mathrm{m}$ and $347 \pm 39 \mu \mathrm{m}$, respectively (Fig. 4f), with coefficients of variation of about 20\% (Fig. 4g). Interestingly, the effect of DS on aggregate size was not significant during the exponential growth phase of culture. Individual aggregate diameters are also similar between both supplemented media, following comparable distributions for all culture days (Fig. 4h, i).

Considerable glucose depletion was found for both media, with as little as 28 and $8 \%$ of fresh medium values at day 7 for mTeSR $1+D S$ and mTeSR3D + DS, respectively (Fig. 4j), and lactate was built-up until nearly $20 \mathrm{mM}$ (Fig. 4k). For mTeSR1 + DS, following a yield of lactate from glucose of $\sim 2.5$ at day 1 , it stabilised between 1.5 and 1.6 towards the end of culture. For mTeSR3D + DS, this yield was maintained at $\sim 2.0$ for the initial days of culture, but decreased substantially starting from day 3 , reaching a minimum of $\sim 0.7$ (Fig. 4l). This value indicates the metabolism to, most likely, have shifted to being predominantly OXPHOS, in particular with mTeSR3D + DS.

\section{VWBRs do not compromise the pluripotency of the cells}

Although the main purpose of expansion in a bioreactor system is to obtain large numbers of cells, it is important to guarantee that the process does not compromise cell quality, in particular hiPSC pluripotency. For that purpose, hiPSC aggregates were harvested from the PBS MINI 0.1 after culture and stained for both intracellular (OCT4 and SOX2) and surface (TRA-1-60 and SSEA-4) pluripotency markers. Figure 5a shows representative images, demonstrating the presence of these markers after 7 days of expansion. Cell aggregates were also dissociated into single cells with Accutase and replated on Matrigel-coated 2D tissue culture plates. These cells were able to form hiPSC colonies in these conditions and representative images show expression of the aforementioned markers (Fig. 5b). Assessment of the differentiation potential of the expanded cells was performed via the embryoid body (EB) assay (Fig. 5c), where the cells stained for markers of the three germ layers - TUJ1 (ectoderm), $\alpha$-SMA (mesoderm) and SOX17 (endoderm), after 5 weeks of spontaneous differentiation. Expanded hiPSCs were also shown to be able to form both cardiomyocytes (Fig. 5d) and neural progenitors (Fig. 5e) following directed differentiation in 2D.
Quantification of pluripotency and differentiation marker expression was performed through both flow cytometry and quantitative real-time polymerase chain reaction (qRT-PCR) analyses. Flow cytometry analyses (Fig. $5 \mathrm{f}$ and Additional file 1: Figure S2) revealed that, for all conditions, following 7 days of expansion in the VWBR, expression of pluripotency markers OCT4 and TRA-1-60 was always above $90 \%$ and expression of early differentiation surface marker SSEA-1 was maintained at less than $10 \%$. Before and after expansion, total RNA was extracted from cell samples and the expression of pluripotency (OCT4 and NANOG) and differentiation genes, namely SOX1 (ectoderm), T/BRACHYURY (mesoderm) and SOX17 (endoderm), were assayed through qRT-PCR (Fig. 5g). Expression of pluripotency genes OCT4 and NANOG was high and not significantly different between days 0 and 7 , while the expression of the differentiation markers was maintained low. In general, all these results point out the VWBR not to compromise the pluripotency of the cells throughout the expansion process.

\section{Discussion}

Therapeutic or pharmacological applications of hiPSCs require high numbers of cells. High cell densities of hPSCs have been previously attained using spinner flasks and stirred tank bioreactors, both using microcarriers as a culture support, or growing the cells as self-forming aggregates. However, some characteristics of these reactors, namely the low efficiency to keep in suspension particles such as cell-loaded microcarriers or cell aggregates, or the consequent high shear stress conveyed to the cells by the impeller at high stirring speeds, have led to research on more suitable bioreactor configurations for hPSC growth.

The work here described is intended to establish, in the PBS MINI VWBR, the culture of hiPSCs as floating aggregates. The largest barrier for the usage of this culture format is the aggregate size control [23]. Since in bioreactors aggregate size is influenced by shear stress [34], the VWBR is expected to provide a significant advantage, as its novel agitation mechanism leads to a more homogeneous shear stress distribution than observed in stirred tank bioreactors [17], contributing to a decrease in aggregate size variability and avoiding the formation of very large aggregates.

An overview of the results, already described in the previous section, is shown in Table 1. Initial experiments with the VWBR have shown it to allow for the growth of hiPSCs with $\mathrm{mTeSR} 1$, with high reproducibility between different bioreactor runs and among two cell lines (Fig. 2). Cell density values and volumetric productivities were also amongst those reported in spinner flasks and traditional reactors (Table 2). Culture performance can also be 

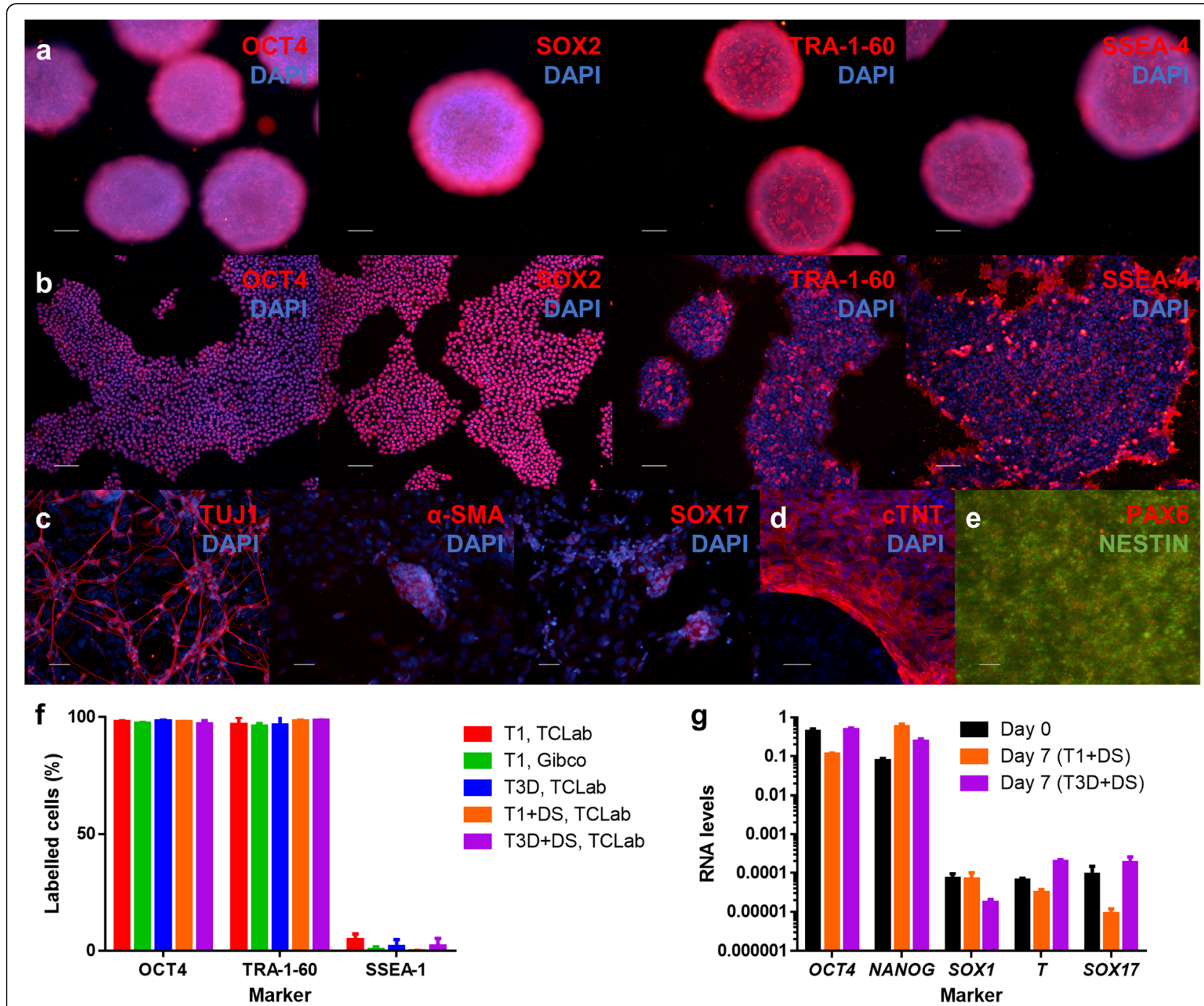

Fig. 5 Characterisation of the hiPSCs following expansion in the PBS MINI 0.1 bioreactor. a-b Immunocytochemistry staining for pluripotency markers OCT4, SOX2, TRA-1-60 and SSEA-4 of cell aggregates harvested from the PBS MINI 0.1 bioreactor at day 7 post-expansion (a; scale bars = $100 \mu \mathrm{m}$ ), and of cells which were dissociated with Accutase and replated on 2D tissue culture plates (b; scale bars $=100 \mu \mathrm{m})$. $\mathbf{c}$

Immunocytochemistry staining of cells harvested from the bioreactor and left to form EBs for 5 weeks. The cells were stained for germ layer markers TUJ1 (ectoderm), a-SMA (mesoderm) and SOX17 (endoderm; scale bars = $50 \mu \mathrm{m}$ ). d-e Immunocytochemistry staining of cells harvested from the bioreactor and differentiated to $\mathbf{d}$ cardiomyocytes and e neural progenitors (scale bars $=50 \mu \mathrm{m}$ ). Cardiomyocytes were stained for cTNT, while neural progenitors were stained for PAX6 and NESTIN. f Flow cytometry analysis of cells harvested from the bioreactor after 7 days of expansion in the PBS MINI 0.1 bioreactor. The cells were labelled for pluripotency (OCT4 and TRA-1-60) and early differentiation (SSEA-1) markers. $\mathbf{g}$ qRT-PCR analysis of cells prior to (day 0) and following (day 7) expansion in the PBS MINI 0.1 bioreactor. The cells were tested for pluripotency (OCT4 and NANOG) and germ layer (SOX1, T/BRACHYURY and SOX17, representing ectoderm, mesoderm and endoderm, respectively) marker expression. RNA levels are relative to expression of GAPDH and were computed as $2^{-\triangle C T}$

favourably compared with hiPSC culture on microcarriers in the VWBR [21], where similar cell densities and volumetric productivities were obtained with the same cell line. Despite this, the culture set-up is barely optimised, as around $60 \%$ of the cells did not aggregate in the first $24 \mathrm{~h}$ of culture and therefore further optimisation should be possible to improve the present results.

Besides the promising results obtained with mTeSR1, a fed-batch feeding regime with mTeSR3D medium was tested as a means of mitigating the drastic parameter variations characteristic of a repeated batch approach, and allowing for the accumulation of growth-inducing paracrine factors [10]. The fed-batch strategy (Fig. 3) resulted in similar growth profiles and aggregate diameter distributions to repeated batch cultures but the high cell densities at the end of culture along with the slow replenishment of glucose and low dilution of lactate may have led to alterations in the metabolism of the cells. Proliferative cells, such as hiPSCs during their exponential growth, favour glycolysis for fast glucose uptake and 
Table 1 Main results for all different tested conditions

\begin{tabular}{|c|c|c|c|c|c|c|c|c|c|c|}
\hline Cell line & $\begin{array}{l}\text { Culture } \\
\text { medium }\end{array}$ & $\begin{array}{l}\text { Fold } \\
\text { change in } \\
\text { cell number } \\
\text { (day 1) }\end{array}$ & $\begin{array}{l}\text { Maximum } \\
\text { number of } \\
\text { cells (cells/ } \\
\text { vessel) }\end{array}$ & $\begin{array}{l}\text { Maximum } \\
\text { cell density } \\
\text { (cells } \mathrm{mL}^{-1} \text { ) }\end{array}$ & $\begin{array}{l}\text { Maximum } \\
\text { fold } \\
\text { increase }\end{array}$ & $\begin{array}{l}\text { Maximum } \\
\text { specific } \\
\text { growth } \\
\text { rate }\left(d^{-1}\right)\end{array}$ & $\begin{array}{l}\text { Minimum } \\
\text { doubling } \\
\text { time (d) }\end{array}$ & $\begin{array}{l}\text { Volumetric } \\
\text { productivity } \\
\text { (cells } m L^{-1} \cdot d^{-1} \text { ) }\end{array}$ & $\begin{array}{l}\text { Maximum } \\
\text { aggregate } \\
\text { diameter } \\
(\mu \mathrm{m})\end{array}$ & $\begin{array}{l}\text { Minimum } \\
\text { coefficient } \\
\text { of variation }\end{array}$ \\
\hline TCLab & mTeSR1 & $0.40 \pm 0.03$ & $\begin{array}{l}(7.1 \pm 0.7) \\
\times 10^{7}\end{array}$ & $\begin{array}{l}(1.2 \pm 0.1) \\
\times 10^{6}\end{array}$ & $4.8 \pm 0.5$ & $0.69 \pm 0.13$ & $1.1 \pm 0.2$ & $(1.7 \pm 0.1) \times 10^{5}$ & $409 \pm 25$ & $28 \pm 6 \%$ \\
\hline Gibco & mTeSR1 & $0.27 \pm 0.08$ & $\begin{array}{l}(6.2 \pm 1.1) \\
\times 10^{7}\end{array}$ & $\begin{array}{l}(1.0 \pm 0.2) \\
\times 10^{6}\end{array}$ & $4.1 \pm 0.7$ & $0.66 \pm 0.05$ & $1.06 \pm 0.09$ & $(1.4 \pm 0.3) \times 10^{5}$ & $338 \pm 27$ & $19.6 \pm 0.6 \%$ \\
\hline TCLab & mTeSR3D & $0.24 \pm 0.03$ & $\begin{array}{l}(6.1 \pm 0.7) \\
\times 10^{7}\end{array}$ & $\begin{array}{l}(8.8 \pm 1.6) \\
\times 10^{5}\end{array}$ & $4.0 \pm 0.5$ & $1.1 \pm 0.1$ & $0.63 \pm 0.06$ & $(1.2 \pm 0.1) \times 10^{5}$ & $367 \pm 18$ & $27 \pm 2 \%$ \\
\hline TCLab & mTeSR1 + DS & $0.38 \pm 0.06$ & $\begin{array}{l}(1.4 \pm 0.1) \\
\times 10^{8}\end{array}$ & $\begin{array}{l}(2.3 \pm 0.2) \\
\times 10^{6}\end{array}$ & $9.3 \pm 0.6$ & $1.1 \pm 0.2$ & $0.64 \pm 0.11$ & $(4.6 \pm 0.3) \times 10^{5}$ & $346 \pm 11$ & $20 \pm 1 \%$ \\
\hline TCLab & mTeSR3D + DS & $0.50 \pm 0.07$ & $\begin{array}{l}(1.26 \pm 0.02) \\
\times 10^{8}\end{array}$ & $\begin{array}{l}(1.79 \pm 0.03) \\
\times 10^{6}\end{array}$ & $8.4 \pm 0.1$ & $0.96 \pm 0.10$ & $0.74 \pm 0.09$ & $(2.99 \pm 0.05) \times 10^{5}$ & $347 \pm 39$ & $19 \pm 2 \%$ \\
\hline
\end{tabular}

to produce all of the molecules required for cell division $[32,33]$. In fact, during the early days of culture, cells were metabolising glucose mainly through glycolysis, indicated by a yield of lactate from glucose close to 2 . The lower yield observed at the end of culture suggests a metabolic shift to OXPHOS, which has already been reported in stirred bioreactor cultures of hiPSC [10]. Still, this is the first successful report indicating the viability of a fed-batch feeding strategy for the dynamic suspension culture of hiPSCs, and its optimisation could greatly increase the performance and the economic viability of this regime. A rough cost estimation based on these results led to the conclusion that mTeSR3D can provide about $10 \%$ reduction in the cost of medium spent per cell obtained. As such, the selection of the optimal medium for culture should be weighted considering the importance of both the cost and the performance.

The VWBR was shown to sustain the growth of hiPSCs with two different feeding regimes and to compare favourably with traditional bioreactor systems. However, given that the maximum cell density obtained was (1.2 \pm $0.1) \times 10^{6}$ cells $\cdot \mathrm{mL}^{-1}$ and that Regenerative Medicine applications can require $10^{9}$ cells, it was considered important to develop strategies to increase the cell yield in the reactor. Additionally, the average size of the aggregates in all conditions exceeded $300 \mu \mathrm{m}$, which is problematic due to the diffusion limitations to the centre of the aggregate. A promising strategy that was found for both increased cell yield and aggregate size control was the supplementation of the culture media with DS. This compound was already reported to have these effects on hPSC aggregates [27] due to its anti-apoptotic activity and surface charge modulation, without compromising pluripotency. In fact, DS supplementation increased cell yields in about two-fold and reduced the period of exponential growth, allowing for faster cultures (Fig. 4). At day 1, we did not observe a reduction in aggregate sizes with DS supplementation (Fig. 4f) but our results suggest that a higher absolute number of aggregates was formed in the presence of DS (Additional file 1: Figure S3). In this regard, we may hypothesize that the increase in cell number resulted from an initial formation of a higher number of aggregates that expanded to a comparable size of those cultured in the non-supplemented media.

The results obtained thus clearly favour DS supplementation of media over its absence, due to the boost in culture performance without any observed negative effect over the hiPSCs. In these conditions, the fed-batch system had a lower overall performance when compared to mTeSR1, in terms of maximum cell yield, productivity and even in the effect on the metabolic activity of the cells.

Table 2 Comparison of aggregate-based suspension culture set-ups for the expansion of hPSCs

\begin{tabular}{|c|c|c|c|c|c|c|c|}
\hline Cell type & $\begin{array}{l}\text { Culture } \\
\text { medium }\end{array}$ & $\begin{array}{l}\text { Bioreactor } \\
\text { type/volume }\end{array}$ & $\begin{array}{l}\text { Inoculum cell } \\
\text { density (cells:mL }{ }^{-1} \text { ) }\end{array}$ & $\begin{array}{l}\text { Days in } \\
\text { culture }\end{array}$ & $\begin{array}{l}\text { Maximum cell } \\
\text { density (cells } \mathrm{mL}^{-1} \text { ) }\end{array}$ & $\begin{array}{l}\text { Volumetric productivity } \\
\left(\text { cells } \cdot \mathrm{mL}^{-1} \cdot \mathrm{d}^{-1} \text { ) }\right.\end{array}$ & Reference \\
\hline hESCs & mTeSR1 & Spinner flask (100 mL) & $1.8 \times 10^{4}$ & 6 & $4.5 \times 10^{5}$ & $7.5 \times 10^{4}$ & [11] \\
\hline hESCs & mTeSR1 & Spinner flask (50 mL) & $1 \times 10^{6}$ & 7 & $2.4 \times 10^{6}$ & $3.4 \times 10^{5}$ & [12] \\
\hline hESCS & StemPro hESC SFM & Spinner flask (60 mL) & $2.5 \times 10^{5}$ & $3-4$ & $(1.1 \pm 0.1) \times 10^{6}$ & $(3.7 \pm 0.3) \times 10^{5}$ & [13] \\
\hline hiPSCs & E8 & Spinner flask (45 mL) & $(4-5) \times 10^{5}$ & $3-4$ & $(1.8 \pm 0.3) \times 10^{6}$ & $(5.8 \pm 0.8) \times 10^{5}$ & [14] \\
\hline hESCs & mTeSR1 & Spinner flask (100 mL) & $2 \times 10^{4}$ & 6 & $(2.4 \pm 0.09) \times 10^{5}$ & $(4.0 \pm 0.2) \times 10^{4}$ & [15] \\
\hline hiPSCs & mTeSR1/E8 & Stirred tank (125 mL) & $5 \times 10^{5}$ & 7 & $(2.85 \pm 0.34) \times 10^{6}$ & $(4.07 \pm 0.49) \times 10^{5}$ & [10] \\
\hline hiPSCs & mTeSR1 & Vertical-Wheel (60 mL) & $2.5 \times 10^{5}$ & 7 & $(1.2 \pm 0.1) \times 10^{6}$ & $(1.7 \pm 0.1) \times 10^{5}$ & This study \\
\hline hiPSCs & mTeSR1 + DS & Vertical-Wheel (60 mL) & $2.5 \times 10^{5}$ & 7 & $(2.3 \pm 0.2) \times 10^{6}$ & $(4.6 \pm 0.3) \times 10^{5}$ & This study \\
\hline
\end{tabular}


It is important to note that the pluripotency and viability of the cells cultured under the optimal condition, mTeSR1 + DS, was not affected in the VWBR (Fig. 5). Indeed, after 7 days of culture, cells continued to express pluripotency markers, were able to form EBs, containing representatives of the three germ layers and to generate both cardiomyocytes and neural progenitors following directed differentiation into these lineages. At the end of the culture, cell aggregates reached over $300 \mu \mathrm{m}$ in diameter, indicating some of the larger aggregates to be prone to diffusional limitations of nutrients and oxygen. While this could translate to necrosis in the centre of the aggregate, calcein AM/ethidium homodimer staining and confocal microscopy analysis as well as LIVE/DEAD flow cytometry (Additional file 1: Figure S4) show that dead cells are present in minority, and that there is no clear dead mass in the centre of the aggregate. Nevertheless, more prolonged culture of these cells would likely require dissociation and passaging to new culture vessels in order to maintain their viability and pluripotency over longer periods of time. Increasing the agitation at later days of culture could also reduce the diameter of the aggregates, allowing for better diffusion, while also contributing to a reduction in the variation in diameter size.

This study shows that VWBR can be considered a viable alternative for the growth of hPSCs, generating cell densities well within the range of those obtained with other types of bioreactors (Table 2), while maintaining pluripotency. Nevertheless, there are still some challenges to tackle with this culture set-up. Namely, the process is still ill-optimised and a design of experiments (DoE) approach could be employed as a means of maximising the cellular growth and controlling cell aggregation for prospective integrated differentiation approaches inside the bioreactor. The cell yield obtained in this study was $2.3 \times 10^{6}$ cells. $\mathrm{mL}^{-1}$, after 5 days, using a repeated batch feeding strategy. Kropp and co-workers [9] described a $47 \%$ increase in cell yield when the repeated batch feeding was replaced by perfusion, in miniaturised bioreactor systems, allowing for a maximum cell density of $(2.85 \pm 0.34) \times 10^{6}$ cells $\cdot \mathrm{mL}^{-1}$ following 7 days in culture. Herein, the feeding modes used led to glucose depletion and lactate accumulation at later days of culture, especially in the fed-batch culture with mTeSR3D + DS, which may have hindered the achievement of higher cell densities. Operation of the PBS MINI 0.1 VWBR with perfusion is not straightforward but its implementation (either in this model or, prospectively, in higher volume models) would probably allow for higher cell densities to be obtained. Nevertheless, the cell density obtained with the present culture methodology was very close to that obtained by Kropp and co-workers with perfusion and, moreover, in comparison with that same study, our process started from half the cell density and reached the maximum cell density in less time (5 days vs 7 days).

The PBS MINI 0.1 is a scaled-down bioreactor model, designed for process development and optimisation and not for cell production for clinical/industrial use. Assuming that $10^{9}$ cells are required for organ regeneration (e.g. heart or liver [7]), if the highest cell density obtained in this study, $(2.3 \pm 0.2) \times 10^{6}$ cells $\cdot \mathrm{mL}^{-1}$, could be maintained at higher scales, a bioreactor with a working volume of about 450 $\mathrm{mL}$ would be enough to meet the needs for one person. The availability of VWBR up to $80 \mathrm{~L}$ allow to envisage the use of higher volume models to generate cells for allogeneic settings while smaller-scale vessels (e.g. PBS 3), could be suited for an autologous cell product. Independently of the application, it is important to note that the scale-up of hPSCs is often prohibitive due to medium costs and, as such, it is crucial to carefully plan how to perform it, namely in terms of which criteria to apply (constant power input per volume, tip speed, mixing time or oxygen transfer, for instance). A previous study [21] already proved the PBS MINI 0.5, which can hold up to $500 \mathrm{~mL}$, to be compatible with the growth of hiPSCs attached to microcarriers. As such, it would be important to also scale-up cell growth as aggregates, in order to generate a number of cells compatible with clinical and/or pharmacological applications.

\section{Conclusions}

One of the main bottlenecks in the usage of hPSCs in clinical or pharmacological applications is their expansion to large quantities, while maintaining their characteristics. Bioreactors provide major advantages over planar culture platforms, namely in terms of scalability, control and homogeneity, but are still not fully optimised for stem cell growth, as the shear stress caused by the impeller can greatly damage these cells. The VWBRs can mitigate this problem due to their more efficient mixing and gentler agitation set-up. The work here described is one of the first accounts of the usage of the PBS MINI VWBR for hPSC expansion, and the first one to expand the cells as floating aggregates. This system overall has the potential to comply easily with cGMP due to the single-use bioreactor system and the lack of matrices of any kind for cell adherence. The conjunction of mTeSR1 medium with DS led to a maximum increase of $9.3 \pm 0.6$-fold over the inoculum after only 5 days of culture, while not compromising the pluripotency of the cells. Although there are still some challenges to face with this system, namely the usage of xeno-free media, the conversion to perfusion in order to potentially generate larger numbers of cells, and, finally, the scale-up to larger bioreactors, this study provides compelling evidence in the applicability of the VWBRs for the growth of hPSCs for diverse biomedical applications. 


\section{Methods}

\section{Human induced pluripotent stem cell culture and maintenance}

This work was performed using two different hiPSC lines. The F002.1A.13 cell line, (TCLab - Tecnologias Celulares para Aplicação Médica, Portugal), referred to in the text as "TCLab", was reprogrammed from human healthy fibroblasts $(46, \mathrm{XX})$, through retroviral transduction of human genes OCT4, SOX2, C-MYC and KLF4. The Gibco $^{\circ}$ human episomal induced pluripotent stem cell line (Thermo Fisher Scientific, USA), referred to in the text as "Gibco", was derived from CD34 $4^{+}$cord blood through EBNA-based episomal transfection of factors SOX2, OCT4, KLF4, C-MYC, NANOG, LIN28 and SV40 T antigen. The hiPSCs were cultured on 6-well tissue culture plates coated with Matrigel (1:100; Corning, USA), in mTeSR1 culture medium (STEMCELL Technologies, Canada), and kept in a humidified incubator at $37^{\circ} \mathrm{C}$ and $5 \% \mathrm{CO}_{2}$. Culture medium was refreshed daily, and the cells were routinely passaged after reaching $80 \%$ confluence at a split ratio of 1:4, using EDTA (Thermo Fisher Scientific) [35]. Briefly, cells were washed twice and left to incubate for $5 \mathrm{~min}$ with EDTA $\left(0.5 \mathrm{mmol} \cdot \mathrm{L}^{-1}\right.$ in Dulbecco's phosphate-buffered saline, DPBS; Thermo Fisher Scientific). Afterwards, EDTA was removed and the cells were rinsed and collected by pipetting with culture medium before plating in new Matrigel-coated tissue culture plates. Cultures did not exceed four passages prior to bioreactor inoculation.

\section{Bioreactor inoculation and operation}

For this work, the PBS MINI 0.1 MAG VWBRs, which hold a maximum volume of $100 \mathrm{~mL}$, were used. The working volume was selected to allow complete covering of the impeller wheel (initial working volume $=60 \mathrm{~mL}$ ). Cells from $80 \%$ confluent 6 -well tissue culture plates were incubated for $1 \mathrm{~h}$ in mTeSR1 supplemented with $10 \mu \mathrm{mol} \cdot \mathrm{L}^{-1}$ ROCK inhibitor Y-27632 (STEMCELL Technologies) prior to harvesting with Accutase. Briefly, cells were washed once with DPBS and incubated for 7 min at $37^{\circ} \mathrm{C}$ in Accutase (Sigma, USA). The cells were harvested and mechanically dissociated into single cells with a micropipette, and diluted with culture medium, following centrifugation at $210 \times g$ for $3 \mathrm{~min}$ and resuspension in culture medium (mTeSR1 or mTeSR3D, STEMCELL Technologies) supplemented with Y-27632. The hiPSCs were counted with a haemocytometer, using the trypan blue dye exclusion test, and seeded in the bioreactor at a density of 250,000 cells $\cdot \mathrm{mL}^{-1}$. Culture media with Y-27632 was added until reaching the working volume. For culture in mTeSR1, the medium was changed after $48 \mathrm{~h}$ to mTeSR1 without Y-27632, and from then on, $80 \%$ of the volume was changed daily. For culture in mTeSR3D, cells were initially cultured in seed medium, and, starting from $48 \mathrm{~h}$ post-inoculation, $6.7 \mathrm{~mL}$ of feed medium were added daily. At day 4 , the medium was replaced with fresh seed medium, and from then on, 6.7 $\mathrm{mL}$ of feed medium were once again added daily until the end of culture. When used, DS (Sigma) was supplemented only on day 0 at a concentration of $100 \mu \mathrm{g} \cdot \mathrm{mL}^{-1}$ [27]. Bioreactor cultures were maintained for 7 days and the stirring was continuously maintained at $30 \mathrm{rpm}$ to keep the aggregates in suspension.

Culture sampling was performed daily. Two samples of $700 \mu \mathrm{L}$ were collected with the reactor under agitation, and photos of the aggregates were captured with an inverted optical microscope (Leica DMI3000B/Nikon Digital Camera Dxm1200F) for later measurement. At least 50 aggregates were captured and analysed per timepoint. The area of the aggregates in each photo was determined using the FIJI software [36, 37], and their diameter was computed, considering the aggregates to be approximately spherical, as

$$
d=\sqrt{\frac{4 A}{\pi}}
$$

with $\mathrm{A}$ as the area of the aggregate. The dispersion in aggregate size was determined as the coefficient of variation, defined as

$$
C_{V}=\frac{\mathrm{SD}_{d}}{\mu_{d}}
$$

with $\mathrm{SD}_{\mathrm{d}}$ as the standard deviation and $\mu_{\mathrm{d}}$ as the average of the diameter for each condition. The aggregates were incubated with Accutase and mechanically dissociated into single cells as previously described. Viable cells were counted with a haemocytometer. Cell viability was over $90 \%$ at all culture days. Fold increase in cell number at a given time point was calculated as the ratio

$$
\mathrm{FI}=\frac{X}{X_{0}}
$$

with $\mathrm{X}$ as the number of cells at the considered time point, and $\mathrm{X}_{0}$ as the initial number of cells.

The viability of cells in the aggregates was assayed by incubation with $2 \mu \mathrm{mol} \cdot \mathrm{mL}^{-1}$ of calcein AM during 20 min and observation of the stained aggregates under a fluorescence microscope (Leica DMI3000B/Nikon Digital Camera Dxm1200F).

At the end of culture, hiPSC aggregates were incubated for $1 \mathrm{~h}$ in culture medium supplemented with Y27632 following incubation with Accutase and mechanical dissociation into single cells, as previously described, and replating on Matrigel-coated tissue culture plates at a density of $5 \times 10^{4}$ cells $\cdot \mathrm{cm}^{-2}$. 


\section{Glucose and lactate analysis}

Culture supernatants were collected every day prior to and following medium exchange, and centrifuged at $360 \times g$ for $10 \mathrm{~min}$ to remove dead cells and debris. The cell-free supernatants were analysed using an YSI 7100MBS Multi Channel Biochemistry Analyser (Yellow Spring Instruments, USA) for concentrations of glucose and lactate. The apparent yield of lactate from glucose was calculated for each day as

$$
Y_{\mathrm{Lac} / \mathrm{Glc}}=\frac{\Delta \mathrm{Lac}}{\Delta \mathrm{Glc}}
$$

with $\Delta \mathrm{Lac}$ as the production of lactate and $\Delta \mathrm{Glc}$ as the consumption of glucose during a given day of culture.

\section{Flow cytometry}

Throughout culture, cells were collected from the PBS MINI 0.1 and analysed for the expression of pluripotency and differentiation markers. The protocols for staining are described elsewhere for both intracellular [38] and surface markers [21]. For intracellular staining, an antibody for OCT4 (1:300; Millipore, USA) was used, and goat antimouse IgG-AlexaFluor 488 (1:300; Thermo Fisher Scientific) was used both as a secondary antibody and as a negative control. The gate was selected to contain only $1 \%$ of false positives (i.e. $1 \%$ of the negative control samples). For surface staining, cells were labelled with antibodies for TRA-160 (1:10, PE-conjugated; Miltenyi Biotec, Germany) and SSEA-1 (1:20; FITC-conjugated, BioLegend, USA). The gate was selected to contain only $1 \%$ of false positives (i.e. $1 \%$ of the unstained samples). The cell samples were analysed with a FACSCalibur flow cytometer (Becton Dickinson, USA) and acquisition of the data was performed with the Cell Quest software (Becton Dickinson). For data analysis, Flowing Software (University of Turku, Finland) was used. A minimum of 10,000 events were analysed for each sample.

\section{Immunocytochemistry}

Both replated cells and aggregates were stained using previously described protocols for both intracellular [38] and surface markers [21]. For intracellular staining of hiPSCs, antibodies for OCT4 (1:150; Millipore) and SOX2 (1:200; R\&D Systems, USA) were used, and goat anti-mouse IgGAlexaFluor 546 (1:500; Thermo Fisher Scientific) was used as a secondary antibody. For surface staining of hiPSCs, cells were labelled with antibodies for TRA-1-60 (1:135, StemGent, USA) and SSEA-4 (1:135; StemGent) with the secondary antibody goat anti-mouse IgM-AlexaFluor 546 (1:500; Thermo Fisher Scientific) or goat anti-mouse IgGAlexaFluor 546 (1:500), respectively. Staining of EBs was performed with antibodies for TUJ1 (1:1000; Covance, USA), $\alpha$-SMA (1:200; Dako, Denmark), and SOX17 (1:100; R\&D Systems). Staining following directed differentiation was performed with cTNT (1:200; Thermo Fisher Scientific) for cardiac differentiation, and PAX6 (1:400; Covance) and NESTIN (1:400; R\&D Systems) for neural differentiation. Secondary staining was performed with goat antimouse IgG-AlexaFluor 546 (1:500), goat anti-rabbit IgGAlexaFluor 546 (1:500, Thermo Fisher Scientific) or goat anti-mouse IgG-AlexaFluor 488 (1:500; Thermo Fisher Scientific). In all cases, nuclei were counterstained by incubation with DAPI (1.5 $\mu \mathrm{g} \cdot \mathrm{mL}^{-1}$; Sigma) for $5 \mathrm{~min}$. Stained cells were analysed under a fluorescence microscope.

\section{qRT-PCR}

Total RNA from frozen cell pellets was extracted using the High Pure RNA Isolation Kit (Roche, Switzerland). Following quantification in a NanoVue ${ }^{\text {TM }}$ Plus spectrophotometer (GE Healthcare, USA), $1 \mu \mathrm{g}$ of RNA was converted to cDNA using the High-Capacity cDNA Reverse Transcriptase Kit (Life Technologies). Reactions were run in triplicate using NZYSpeedy qPCR Green Master Mix, ROX plus (NZYTech, Portugal), and primers specific for OCT4, NANOG, SOX1, T/BRACHY$U R Y$ and $S O X 17$ in a StepOne Plus Real-Time PCR System (Thermo Fisher Scientific). $C_{T}$ values for each condition were normalised against the corresponding expression of the housekeeping gene glyceraldehyde-3phosphate dehydrogenase $(G A P D H)$, generating $\Delta \mathrm{C}_{\mathrm{T}}$. RNA levels were computed as $2^{-\Delta C T}$.

\section{Differentiation potential assays}

The differentiation potential of hiPSCs was evaluated through the EB assay. Following harvesting of cells from the PBS MINI 0.1, they were replated on 6-well ultra-low attachment tissue culture plates (Corning) in mTeSR1 supplemented with Y-27632. After $24 \mathrm{~h}$, the medium was changed to EB medium, containing KnockOut (KO)-Dulbecco's Modified Eagle's Medium (DMEM) supplemented with 20\% foetal bovine serum (FBS), 1\% (V/V) Minimum Essential Medium (MEM) non-essential amino acids, 1 $\mathrm{mmol} \cdot \mathrm{L}^{-1} \mathrm{~L}$-glutamine and $1 \%(\mathrm{~V} / \mathrm{V})$ penicillin/streptomycin (all from Thermo Fisher Scientific), which was refreshed every 2 days during 4 weeks. After differentiation, the EBs were dissociated using 0.05\% Trypsin-EDTA (Thermo Fisher Scientific) and plated on a 24-well tissue culture plate coated with $15 \mu \mathrm{g} \cdot \mathrm{mL}^{-1}$ poly-ornithine (Sigma) and $20 \mu \mathrm{g} \cdot \mathrm{mL}^{-1}$ laminin (Sigma). EB medium was changed every 2 days during 1 week, after which the cells were stained for TUJ1, $\alpha$-SMA and SOX17. Directed differentiation into both cardiomyocytes and neural progenitors was also performed. Cardiac differentiation was performed through temporal modulation of the WNT signalling pathway $[39,40]$. Briefly, hiPSCs were plated on a 12-well Matrigel-coated tissue culture plate at a density of 100,000 cells $\mathrm{cm}^{-2}$. After reaching $100 \%$ confluence, the medium was changed to RPMI/B27-ins (RPMI 1640 medium 
(Thermo Fisher Scientific), supplemented with $1 \times$ B-27 minus insulin (Thermo Fisher Scientific)), with $6 \mu \mathrm{mol} \cdot \mathrm{L}^{-1}$ of CHIR99021 (StemGent). After $24 \mathrm{~h}$, the medium was changed to RPMI/B27-ins. At day 3, a half-medium change was performed with RPMI/B27-ins supplemented with IWP-4 (StemGent) to a final concentration of $5 \mu \mathrm{mol} \cdot \mathrm{L}^{-1}$, which was removed with the medium change at day 5 . Starting from day 7, the medium was changed every 3 days to RPMI/B27 (RPMI 1640 medium supplemented with 1× B-27 (Thermo Fisher Scientific)) until day 15, when the cells were fixed and stained for cTNT. Neural induction was performed through the dual-SMAD inhibition protocol [41, 42]. Briefly, hiPSCs were plated on a 24-well Matrigelcoated tissue culture plate at a density of 50,000 cells $\mathrm{cm}^{-2}$. After reaching $100 \%$ confluence, the medium was changed to N2B27, a 1:1 mixture of DMEM/F12 and Neurobasal medium with $1 \times \mathrm{N} 2$ and $1 \times \mathrm{B}-27$, respectively (all from Thermo Fisher Scientific), supplemented with $10 \mu \mathrm{mol} \cdot \mathrm{L}^{-1}$ of SB431542 (Sigma) and $100 \mathrm{nmol} \cdot \mathrm{L}^{-1}$ of LDN193189 (StemGent). Complete medium was refreshed daily for 12 days, after which the cells were fixed and stained for PAX6 and NESTIN.

\section{Statistical analyses}

At least three biological replicates were performed for each experiment. Data are expressed as the mean \pm standard error of the mean (SEM). Statistical analyses were performed using GraphPad Prism 6 (GraphPad Software, USA). Statistical significance was determined by two-way ANOVA followed by Tukey's multiple comparisons test. Differences were considered statistically significant at $* p<0.05,{ }^{* *} p<0.01$ and ${ }^{* * *} p<0.001$.

\section{Supplementary information}

Supplementary information accompanies this paper at https://doi.org/10. 1186/s13036-019-0204-1.

Additional file 1: Figure S1. Statistical analysis of hiPSC growth curves. A set of two different culture conditions is presented in each graph: a mTeSR1 vs. mTeSR1 + DS; $\mathbf{b}$ mTeSR3D vs mTeSR3D + DS; c mTeSR1 + DS vs mTeSR3D + DS. Differences between conditions, at a given day, were considered statistically significant at ${ }^{* *} p<0.01$ and ${ }^{* * *} p<0.001$. Figure S2. Flow cytometry analysis of hiPSCs cultured in the WWBR under the different conditions tested: a mTeSR1; b Gibco hiPSC line, mTeSR1; c mTeSR3D; d mTeSR1 + DS; e mTeSR3D + DS. For each condition, representative images of a $2 \mathrm{D}$ dot plot showing population gating and histograms of OCT4, TRA-1-60 and SSEA-1 analyses, including negative controls (grey) are shown. Figure S3. Number of hiPSC aggregates at day 1 under the different culture conditions tested. Samples (700 $\mathrm{LL}$ ) harvested from the WWBR at day 1 were placed in a 24-well tissue culture plate and, using an optical microscope, pictures were taken, capturing all the aggregates present. Images were then analysed to count the total number of aggregates in the sample, which allowed to estimate the number of aggregates in the whole vessel. A total of two samples from two different runs were analysed for each condition. Figure S4. Cell viability analysis. hiPSC aggregates cultured for $\mathbf{a} 3$ and $\mathbf{b}, \mathbf{c} 7$ days in the WWBR, with mTeSR1 +DS, were harvested, incubated with calcein AM $(2 \mu \mathrm{M})$ and ethidium homodimer ( $4 \mu \mathrm{M}$; Sigma) for $30 \mathrm{~min}$ and visualised using a confocal microscope. Maximum intensity projections are shown (scale bars $=100 \mu \mathrm{m}$ ). Aggregates at day 7 were also dissociated, stained with the LIVE/DEAD Fixable Far Red Dead Cell Stain Kit (ThermoFisher), according to the manufacturer instructions and analysed by flow cytometry. Representative images of $\mathbf{d}$ a $2 \mathrm{D}$ dot plot showing population gating and $\mathbf{e}$ an histogram of a sample analysis (orange), including the control (a 50/50 mix of live cells and dead cells obtained by thermal shock) (grey). Three independent samples were analysed and percentage of live cells is shown as mean \pm SEM. Figure $\mathbf{S} 5$ Negative control of the antibody stainings performed in Fig. 5c. Differentiated cells were stained for OCT4 (secondary antibody: goat anti-mouse IgG-AlexaFluor 546), which is not present in these cells (scale bar $=50 \mu \mathrm{m}$ ).

\section{Abbreviations}

bFGF: Basic fibroblast growth factor; CGMP: Current Good Manufacturing Practice; DMEM: Dulbecco's Modified Eagle's Medium; DoE: Design of Experiments; DPBS: Dulbecco's phosphate-buffered saline; DS: Dextran sulfate; EB: Embryoid body; GAPDH: Glyceraldehyde-3-phosphate dehydrogenase; hESC: Human embryonic stem cell; hiPSC: Human induced pluripotent stem cell; hPSC: Human pluripotent stem cell; KO: KnockOut; MEM: Minimum Essential Medium; OXPHOS: Oxidative phosphorylation; qRT-PCR: Quantitative real-time polymerase chain reaction; SEM: Standard error of the mean; TGF $\beta$ : Transforming growth factor $\beta$; WWBR: Vertical-Wheel bioreactor

\section{Acknowledgements}

Not applicable.

\section{Authors' contributions}

DESN, CAVR, CCM, BL, YH, SJ, JMSC designed the study; DESN performed the bioreactor cultures and cell analysis; MSC performed the directed differentiation experiments; DESN, CAVR and JMSC analysed the results and wrote the paper. All authors read and approved the final manuscript.

\section{Funding}

The authors acknowledge financial support from Fundação para a Ciência e a Tecnologia (FCT), Portugal and from Programa Operacional Regional de Lisboa 2020 (Project N. 007317) through iBB - Institute for Bioengineering and Biosciences (UID/BIO/04565/2019). The authors also acknowledge the funding received from the FCT project "CARDIOWHEEL" (PTDC/EQU-EQU/ 29653/2017) and Programa Operacional Regional de Lisboa 2020 through the project PRECISE - Accelerating progress toward the new era of precision medicine (Project N. 16394) and by the DISCOVERIES CTR from EU Teaming Phase2 (H2020-WIDESPREAD-01-2016-2017).

DESN thanks FCT for financial support (PD/BD/128376/2017).

\section{Availability of data and materials}

The datasets used and/or analysed during the current study are available from the corresponding author on reasonable request.

\section{Ethics approval and consent to participate}

Not applicable.

\section{Consent for publication}

Not applicable.

\section{Competing interests}

Authors YH and RW are employees of PBS Biotech. The author BL is CEO and co-founder of PBS Biotech, Inc. These collaborating authors participated in the development of the bioreactors used in the manuscript. This does not alter the authors' adherence to all the policies of the journal on sharing data and materials. All other authors declare no conflict of interest.

\section{Author details}

'Department of Bioengineering and $\mathrm{BB}$, Institute for Bioengineering and Biosciences, Instituto Superior Técnico, Universidade de Lisboa, Av. Rovisco Pais, 1049-001 Lisbon, Portugal. ${ }^{2}$ The Discoveries Centre for Regenerative and Precision Medicine, Lisbon Campus, Instituto Superior Técnico, Universidade de Lisboa, Lisbon, Portugal. ${ }^{3}$ PBS Biotech, Camarillo, CA, USA. 
Received: 12 June 2019 Accepted: 4 September 2019

\section{Published online: 14 September 2019}

\section{References}

1. Rowe RG, Daley GQ. Induced pluripotent stem cells in disease modelling and drug discovery. Nat Rev Genet. 2019;20(7):377-88.

2. Shi $Y$, Inoue $H$, Wu JC, Yamanaka S. Induced pluripotent stem cell technology: a decade of progress. Nat Rev Drug Discov. 2017;16(2):115-30.

3. Takahashi K, Tanabe K, Ohnuki M, Narita M, Ichisaka T, Tomoda K, et al. Induction of pluripotent stem cells from adult human fibroblasts by defined factors. Cell. 2007;131(5):861-72.

4. Yu J, Vodyanik MA, Smuga-Otto K, Antosiewicz-Bourget J, Frane JL, Tian S, et al. Induced pluripotent stem cell lines derived from human somatic cells. Science. 2007;318(5858):1917-20.

5. Itzhaki I, Maizels L, Huber I, Zwi-Dantsis L, Caspi O, Winterstern A, et al. Modelling the long QT syndrome with induced pluripotent stem cells. Nature. 2011;471(7337):225-9.

6. Sayed N, Liu C, Wu JC. Translation of human-induced pluripotent stem cells: from clinical trial in a dish to precision medicine. J Am Coll Cardiol. 2016; 67(18):2161-76.

7. Zweigerdt R. Large scale production of stem cells and their derivatives. Adv Biochem Eng Biotechnol. 2009;114:201-35.

8. Rodrigues CA, Fernandes TG, Diogo MM, da Silva CL, Cabral JM. Stem cell cultivation in bioreactors. Biotechnol Adv. 2011;29(6):815-29.

9. Bauwens C, Yin T, Dang S, Peerani R, Zandstra PW. Development of a perfusion fed bioreactor for embryonic stem cell-derived cardiomyocyte generation: oxygen-mediated enhancement of cardiomyocyte output. Biotechnol Bioeng. 2005;90(4):452-61.

10. Kropp C, Kempf H, Halloin C, Robles-Diaz D, Franke A, Scheper T, et al. Impact of feeding strategies on the scalable expansion of human pluripotent stem cells in single-use stirred tank bioreactors. Stem Cells Transl Med. 2016;5(10):1289-301.

11. Chen VC, Couture SM, Ye J, Lin Z, Hua G, Huang HI, et al. Scalable GMP compliant suspension culture system for human ES cells. Stem Cell Res. 2012:8(3):388-402.

12. Hunt MM, Meng G, Rancourt DE, Gates ID, Kallos MS. Factorial experimental design for the culture of human embryonic stem cells as aggregates in stirred suspension bioreactors reveals the potential for interaction effects between bioprocess parameters. Tissue Eng Part C Methods. 2014;20(1):76-89.

13. Krawetz R, Taiani JT, Liu S, Meng G, Li X, Kallos MS, et al. Large-scale expansion of pluripotent human embryonic stem cells in stirred-suspension bioreactors. Tissue Eng Part C Methods. 2010;16(4):573-82.

14. Singh H, Mok P, Balakrishnan T, Rahmat SN, Zweigerdt R. Up-scaling single cell-inoculated suspension culture of human embryonic stem cells. Stem Cell Res. 2010;4(3):165-79.

15. Wang Y, Chou BK, Dowey S, He C, Gerecht S, Cheng L. Scalable expansion of human induced pluripotent stem cells in the defined xeno-free E8 medium under adherent and suspension culture conditions. Stem Cell Res. 2013;11(3):1103-16.

16. Rodrigues CAV, Nogueira DES, Cabral JMS. Next-generation stem cell expansion technologies. Cell and Gene Therapy Insights. 2018;4(8):791-804.

17. Croughan MS, Giroux D, Fang D, Lee B. Novel single-use bioreactors for scale-up of Anchorage-dependent cell manufacturing for cell therapies. In: CLd S, Chase LG, Diogo MM, editors. Stem Cell Manufacturing. Cambridge: Elsevier; 2016. p. 105-39.

18. de Sousa PD, Bandeiras C, de Almeida FM, Rodrigues CAV, Jung S, Hashimura Y, et al. Scalable Manufacturing of Human Mesenchymal Stromal Cells in the Vertical-Wheel Bioreactor System: An Experimental and Economic Approach. Biotechnol J. 2019:14:e1800716.

19. Sousa MF, Silva MM, Giroux D, Hashimura Y, Wesselschmidt R, Lee B, et al. Production of oncolytic adenovirus and human mesenchymal stem cells in a single-use, vertical-wheel bioreactor system: impact of bioreactor design on performance of microcarrier-based cell culture processes. Biotechnol Prog. 2015:31(6):1600-12.

20. Yuan X, Tsai AC, Farrance I, Rowley J, Ma T. Aggregation of culture expanded human mesenchymal stem cells in microcarrier-based bioreactor. Biochem Eng J. 2018;131:39-46.

21. Rodrigues CAV, Silva TP, Nogueira DES, Fernandes TG, Hashimura Y, Wesselschmidt $R$, et al. Scalable culture of human induced pluripotent cells on microcarriers under xeno-free conditions using single-use vertical-wheel (TM) bioreactors. J Chem Technol Biotechnol. 2018;93(12):3597-606.
22. Serra M, Brito C, Correia C, Alves PM. Process engineering of human pluripotent stem cells for clinical application. Trends Biotechnol. 2012:30(6):350-9.

23. Wu J, Rostami MR, Cadavid Olaya DP, Tzanakakis ES. Oxygen transport and stem cell aggregation in stirred-suspension bioreactor cultures. PLoS One. 2014;9(7):e102486.

24. Dee KU, Shuler ML, Wood HA. Inducing single-cell suspension of BTI-TN5B14 insect cells: I. the use of sulfated polyanions to prevent cell aggregation and enhance recombinant protein production. Biotechnol Bioeng. 1997; 54(3):191-205.

25. Zanghi JA, Renner WA, Bailey JE, Fussenegger M. The growth factor inhibitor suramin reduces apoptosis and cell aggregation in protein-free CHO cell batch cultures. Biotechnol Prog. 2000;16(3):319-25.

26. Hyoung Park J, Sin Lim M, Rang Woo J, Won Kim J, Min LG. The molecular weight and concentration of dextran sulfate affect cell growth and antibody production in CHO cell cultures. Biotechnol Prog. 2016;32(5):1113-22.

27. Lipsitz YY, Tonge PD, Zandstra PW. Chemically controlled aggregation of pluripotent stem cells. Biotechnol Bioeng. 2018;115(8):2061-6.

28. Ludwig TE, BergendahI V, Levenstein ME, Yu J, Probasco MD, Thomson JA. Feeder-independent culture of human embryonic stem cells. Nat Methods. 2006;3(8):637-46.

29. Ludwig TE, Levenstein ME, Jones JM, Berggren WT, Mitchen ER, Frane JL, et al. Derivation of human embryonic stem cells in defined conditions. Nat Biotechnol. 2006;24(2):185-7.

30. Chen X, Chen A, Woo TL, Choo AB, Reuveny S, Oh SK. Investigations into the metabolism of two-dimensional colony and suspended microcarrier cultures of human embryonic stem cells in serum-free media. Stem Cells Dev. 2010;19(11):1781-92.

31. Horiguchi I, Urabe Y, Kimura K, Sakai Y. Effects of glucose, lactate and basic FGF as limiting factors on the expansion of human induced pluripotent stem cells. J Biosci Bioeng. 2018;125(1):111-5.

32. Vander Heiden MG, Cantley LC, Thompson CB. Understanding the Warburg effect: the metabolic requirements of cell proliferation. Science. 2009; 324(5930):1029-33.

33. Varum S, Rodrigues AS, Moura MB, Momcilovic O, Easley CA IV, RamalhoSantos J, et al. Energy metabolism in human pluripotent stem cells and their differentiated counterparts. PLoS One. 2011;6(6):e20914.

34. Sen A, Kallos MS, Behie LA. Expansion of mammalian neural stem cells in bioreactors: effect of power input and medium viscosity. Brain Res Dev Brain Res. 2002;134(1-2):103-13.

35. Beers J, Gulbranson DR, George N, Siniscalchi LI, Jones J, Thomson JA, et al. Passaging and colony expansion of human pluripotent stem cells by enzyme-free dissociation in chemically defined culture conditions. Nat Protoc. 2012;7(11):2029-40.

36. Rueden $\mathrm{CT}$, Schindelin J, Hiner MC, DeZonia BE, Walter AE, Arena ET, et al. ImageJ2: ImageJ for the next generation of scientific image data. BMC Bioinformatics. 2017:18(1):529.

37. Schindelin J, Arganda-Carreras I, Frise E, Kaynig V, Longair M, Pietzsch T, et al. Fiji: an open-source platform for biological-image analysis. Nat Methods. 2012;9(7):676-82.

38. Rodrigues CA, Diogo MM, da Silva CL, Cabral JM. Microcarrier expansion of mouse embryonic stem cell-derived neural stem cells in stirred bioreactors. Biotechnol Appl Biochem. 2011;58(4):231-42.

39. Lian X, Hsiao C, Wilson G, Zhu K, Hazeltine LB, Azarin SM, et al. Robust cardiomyocyte differentiation from human pluripotent stem cells via temporal modulation of canonical Wnt signaling. Proc Natl Acad Sci U S A. 2012;109(27):E1848-57

40. Lian X, Zhang J, Azarin SM, Zhu K, Hazeltine LB, Bao X, et al. Directed cardiomyocyte differentiation from human pluripotent stem cells by modulating Wnt/beta-catenin signaling under fully defined conditions. Nat Protoc. 2013;8(1):162-75

41. Chambers SM, Fasano CA, Papapetrou EP, Tomishima M, Sadelain M, Studer L. Highly efficient neural conversion of human ES and iPS cells by dual inhibition of SMAD signaling. Nat Biotechnol. 2009;27(3):275-80.

42. Fernandes TG, Duarte ST, Ghazvini M, Gaspar C, Santos DC, Porteira AR, et al. Neural commitment of human pluripotent stem cells under defined conditions recapitulates neural development and generates patient-specific neural cells. Biotechnol J. 2015;10(10):1578-88.

\section{Publisher's Note}

Springer Nature remains neutral with regard to jurisdictional claims in published maps and institutional affiliations. 